\title{
Experimental Behaviour of Carbon FRP Reinforced Concrete Beams at Ambient and Elevated Temperatures
}

\author{
Muhammad Masood Rafi ${ }^{1}$ and Ali Nadjai ${ }^{2}$
}

Received 18 May 2008, accepted 19 September 2008

\begin{abstract}
The applications of fibre reinforced polymer (FRP) bars in buildings can provide a potential market for their use. Since buildings may be exposed to elevated temperatures, the behaviour of carbon FRP (CFRP) reinforced concrete (RC) beams was studied at high temperatures and compared with normal temperature behaviour. Steel RC beams were used as control specimens. The failure modes of beams at normal and elevated temperatures were found to be the same. The stiffness of cracked FRP RC was less than steel reinforced concrete at normal temperature whereas FRP reinforced beams were stiffer than steel RC beams at elevated temperatures.
\end{abstract}

\section{Introduction}

Oxidation of steel in reinforced concrete (RC) structures poses serious durability problems and the maintenance of these structures requires costly solutions. Although several preventive measures, such as the use of admixtures in concrete in order to reduce its permeability, the use of galvanized or epoxy-coated steel bars, electrostatic spray fusion-bonded (powder resin) coatings on rods, polymer-impregnated concrete, cathodic protection, etc., were tried in the past, none of these proved successful to avoid steel corrosion. Besides, these methods were either expensive or they complicated initial construction. The introduction of non-metallic fibre reinforced polymer (FRP) bars as an alternative to traditional steel is another attempt towards durable RC construction. High corrosion resistance and high strengthto-weight ratio are the major advantages of FRP bars over steel. Research on fibre bars over the last 25 years has come a long way and has been formulated in the form of design codes (JSCE 1997; ACI 2006; CSA 2002) for the guidance and convenience of practising engineers and professionals. However, there are many outstanding issues that have not yet been thoroughly addressed. Most importantly, there is a wide gap in the current research on FRP RC at elevated temperatures. A literature review carried out by Rafi (2007) showed that only limited research has been conducted regarding the behaviour of FRP RC at high temperatures.

While the behaviour of FRP bar RC structures has been found satisfactory at ambient temperature, information regarding their performance at elevated temperatures is still lacking. This lack of comprehensive knowledge appears to be one of the major obstacles to the

\footnotetext{
${ }^{1}$ Associate Professor, Department of Civil Engineering, NED University of Engineering \& Technology, Pakistan. E-mail:rafi-m@neduet.edu.pk

${ }^{2}$ Professor, FireSERT, University of Ulster, UK.
}

application of fibre bars in residential and commercial buildings as these can be exposed to high temperatures during their service life. International codes are cautious and do not recommend the use of fibre bars in fire owing to inadequate information on the behaviour of FRP $\mathrm{RC}$ in these conditions.

Commercially available fibres include aramid, carbon and glass. Most research activities concentrated on glass FRP (GFRP) owing to their lower cost (Mota et al. 2006; Al-Sunna 2006; Abdalla 2002). Carbon FRP (CFRP) bars are usually preferred in prestressing applications as their tensile strength is comparable with that of prestressing strands. This study reports the results of experimental testing of beams reinforced with CFRP bars. These tests were conducted both at normal and elevated temperatures. Similar steel reinforced beams were also tested as control specimens. A comparison of modes of failure and deflection characteristics has been made for these beams and differences in the beam behaviour both at ambient and high temperatures have been identified and discussed.

\section{Experimental programme}

\subsection{Test specimens}

The overall and effective beam lengths were $2000 \mathrm{~mm}$ and $1750 \mathrm{~mm}$, respectively, whereas the cross section was $120 \times 200 \mathrm{~mm}$. Each of these beams was reinforced with two longitudinal bars on the tension face (CFRP bars for FRP reinforced beams and steel bars for steel reinforced beams). The beams were cast in moulds made of plywood stiffened with aluminium angles to maintain the beam shape under the pressure of newly cast concrete. A $20 \mathrm{~mm}$ concrete cover was used all around the beam. The area and nominal yield strength of the compression steel and nominal concrete strength were kept constant for all beams. Mixing of concrete was done in a rotating mixer. A vibrating table was used for the compaction of concrete inside the mould. The sides of the mould were stripped after 24 hours of cast- 
ing and beams were covered with hessian. Intermittent curing (thrice a day in summer) was carried out for 10 days and then the room temperature test beams were left air-drying in laboratory conditions until the day of testing. Elevated temperature test beams were transferred to the conditioning room to allow the concrete to acquire stable moisture characteristics. The temperature and relative humidity were maintained at $21^{\circ} \mathrm{C}$ to $25^{\circ} \mathrm{C}$ and 40 to $60 \%$, respectively, in the conditioning room according to the British Standard (1999). Four $100 \mathrm{~mm}$ cubes were cast for each beam. Cubes were cured by keeping them on top of their respective beam. The beams were tested under a four-point static load as shown in Fig. 1. The loads were $400 \mathrm{~mm}$ apart giving a shear span of $675 \mathrm{~mm}$.

\subsection{Concrete}

Identical concrete mixes of $325 \mathrm{Kg} / \mathrm{m}^{3}$ of ordinary Portland cement, $1001 \mathrm{Kg} / \mathrm{m}^{3}$ of graded crushed stone, 853 $\mathrm{Kg} / \mathrm{m}^{3}$ of sand and 216 litres $/ \mathrm{m}^{3}$ of water were used to cast the beams. The maximum aggregate size was 10 $\mathrm{mm}$. The exact amount of water varied depending on the moisture content of aggregates. The slump of concrete ranged from 40 to $50 \mathrm{~mm}$. Cube strength after 28 days was $45.88 \mathrm{MPa}$, this being the average strength of the six cubes, one from each beam. This is equivalent to 40.60 MPa cylindrical strength (Neville 1981, p. 544). Table 1 shows the equivalent cylindrical strength, $f_{c}$ (Neville 1981, p. 544) of concrete on the day of testing. These strengths were obtained from the average strength of three cubes for each beam. The tests on duplicate beams were repeated to assess the repeatability and reproducibility of results keeping all the parameters the same. Each beam tested is defined by letters comparing its reinforcing material and temperature conditions. The notation of each beam is as follows: the first letter (B) stands for beam; the second letter indicates the testing temperature as $\mathrm{R}$ for room temperature and $\mathrm{E}$ for ele- vated temperature; the third letter represents the type of tension reinforcing bar material such as $\mathrm{S}$ for steel and $\mathrm{C}$ for CFRP; the letter in italic provides the number of layers, e.g. $S$ for single layer; the following number signifies the clear cover and the numeral at the end is the specimen number. This notation is consistently followed throughout this paper.

\subsection{CFRP bars}

The FRP bars consisted of $9.5 \mathrm{~mm}$ diameter straight CFRP rods, as shown in Fig. 2. The bars were produced by an American manufacturer using the pultrusion process. Continuous carbon fibres with a volume fraction of $60 \%$ by volume were used. The nominal tensile strength and tensile modulus of these fibres were $4.83 \mathrm{GPa}$ and $234 \mathrm{GPa}$, respectively. The resin used to bond fibres was bisphenol epoxy vinyl ester. A textured surface was provided on the bar through surface treatment in order to increase the bond with the concrete. The bar had a widely spaced spiral winding imprint with textured surface in between helical rings. The surface texture was formed with the same resin without involving external fibres. The properties of the CFRP bars are given in Table 2.

\subsection{Steel bars}

Tension rebars in steel reinforced beams consisted of 10 $\mathrm{mm}$ diameter high-strength deformed bars, as shown in Fig. 2. The material properties of these bars are provided in Table 2. The bars were chosen because their nominal cross-sectional area was approximately equal to the CFRP bars. Therefore it was possible to position the steel and CFRP bars identically in the control and test beams. Steel reinforcing bars with the same area as that of the CFRP bars were not available. The top bars were of $8 \mathrm{~mm}$ diameter high-strength deformed steel for all beams. Both top and bottom steel bars were hooked at each end (Fig. 1). The mechanical properties of the top

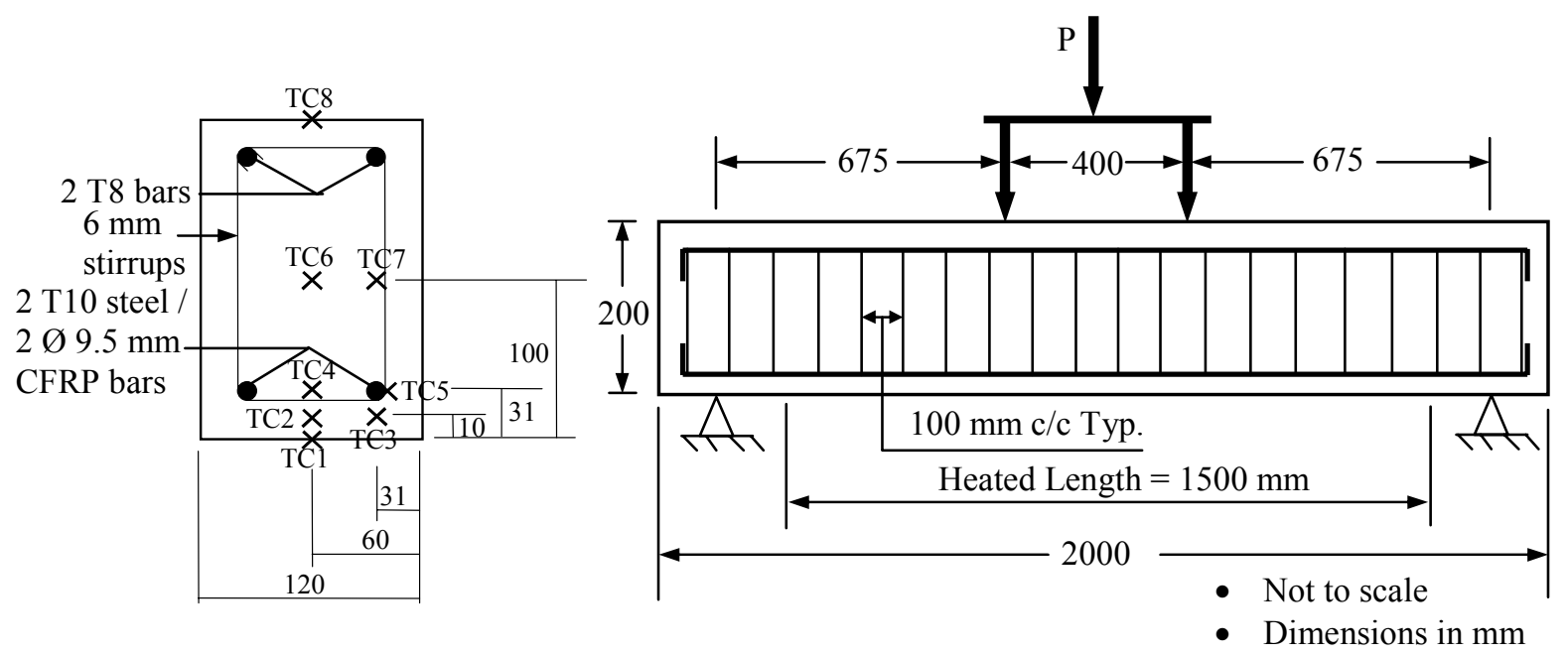

Fig. 1 Details of typical beam. 


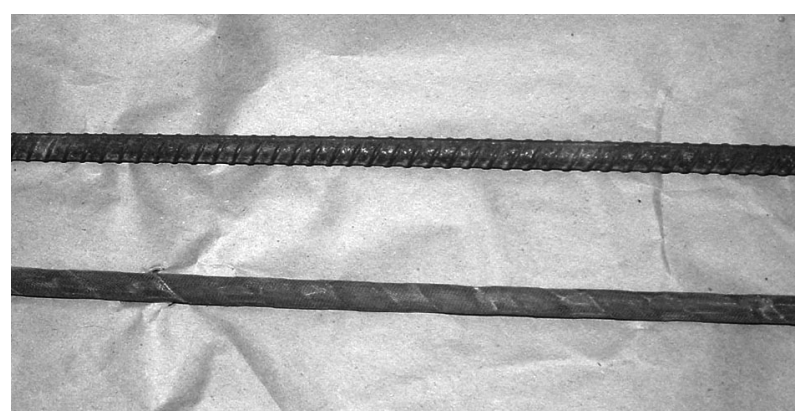

Fig. 2 CFRP and tension steel bar.

Table 1 Properties of beams.

\begin{tabular}{|c|c|c|c|}
\hline Beam & $\begin{array}{c}\text { Tension } \\
\mathrm{R} / \mathrm{F}\end{array}$ & $f_{c}(\mathrm{MPa})$ & Age (Days) \\
\hline BRSS20-1 & Steel & 46.52 & 61 \\
\hline BRSS20-2 & Steel & 44.64 & 85 \\
\hline BECS20-1 & CFRP & 42.55 & 78 \\
\hline BECS20-2 & CFRP & 41.71 & 77 \\
\hline BESS20-1 & Steel & 34.55 & 126 \\
\hline BECS20-1 & CFRP & 45.76 & 106 \\
\hline BECS20-2 & CFRP & 36.13 & 112 \\
\hline
\end{tabular}

Table 2 Mechanical properties of rebars.

\begin{tabular}{|c|c|c|c|}
\hline $\begin{array}{c}\text { Bar type } \\
\text { and } \\
\text { diameter } \\
(\mathrm{mm})\end{array}$ & $\begin{array}{c}\text { Nominal } \\
\text { ultimate } \\
\text { strength* } \\
(\mathrm{MPa})\end{array}$ & $\begin{array}{c}\text { Ultimate } \\
\text { strain* }\end{array}$ & $\begin{array}{c}\text { Elastic } \\
\text { modulus } \\
(\mathrm{GPa})\end{array}$ \\
\hline CFRP - 9.5 & 1676 & 0.0145 & 135.9 \\
\hline Steel - 10 & 530 & 0.0048 & 201 \\
\hline Steel - 8 & 566 & 0.0049 & 194 \\
\hline Steel - 6 & 421 & 0.0041 & 200 \\
\hline
\end{tabular}

*Parameters corresponding to $0.2 \%$ offset yield stress for steel bar

\section{bars are given in Table 2}

The reinforcement cages (Fig. 1) were tied with iron wire. Smooth $6 \mathrm{~mm}$ diameter closed rectangular stirrups spaced at $100 \mathrm{~mm}$ centre to centre were chosen to comply with the criteria of the ultimate strength design of FRP reinforced beams given by ACI code (ACI 2002; 2003). The tensile properties of the $6 \mathrm{~mm}$ bars are also included in Table 2.

\subsection{Instrumentation}

The instrumentation was set up to measure the beam deflection, bar-end slip, temperature and reinforcing bar deformation. Strain gauges were used to measure deformation of tension bars in the room temperature beams. The midspan deflection was monitored using
Linear Variable Differential Transducers (LVDTs). These LVDTs were placed on both sides of the beam at the centre. Horizontal LVDTs were used at the end of FRP RC beams to measure the bar slip. Computer aided data acquisition systems were used to record continuously load, deflection, temperature, slip and strain allowing data to be obtained easily at any time during each test.

\section{Details of furnace}

The floor furnace is 1.5 cubic meter in size internally. The chamber of the furnace is lined with 1550 grade insulating bricks with suitable jointing cement to provide adequate insulation for approximately 6 hours of temperature test. Four burners were used to control the temperature inside the furnace. The beam was positioned over the half round supports on the roof frame of the furnace. The frame was $200 \mathrm{~mm}$ high and was placed on the top of the furnace. The openings in the frame on either side of the beam were closed with RC slabs. These slabs were $200 \mathrm{~mm}$ deep in the outer one half of their width and $50 \mathrm{~mm}$ in the next half close to the sides of the beam, as shown in Fig. 3. The slabs were insulated at the bottom with the help of $25 \mathrm{~mm}$ thick fibre boards exposing around $90 \mathrm{~mm}$ of lateral faces (on each side of the beam soffit) to heating. This arrangement allowed heat exposure to three sides of the beam. The exposed beam length on all three sides was 1500 mm (Fig. 1).

A 10 ton jack was used to apply load on the beam, which was then transferred to the specified points on the test beam by a stiff spreader beam. The jack was connected to the frame in a way to allow easy disconnection for removal of the beam after the test. Five thermocouples were inserted in the furnace to control the fuel input so that the heating conditions could follow the standard curve.

\section{Service load}

The service load is generally considered as $35 \%$ of the ultimate load (Al-Salloum 1996; Nawy and Neuwerth 1977). It appeared in the test of BRCS20 beams that the number of cracks did not increase significantly after an applied load of $30 \mathrm{kN}$. Therefore it was decided to apply a load equal to the larger of $30 \mathrm{kN}$ or $35 \%$ of room temperature ultimate load capacity of the FRP reinforced beams.

The theoretical load capacity of the beam was determined by a section analysis program and this was found reasonably accurate for the BRCS20 and BRSS20 beams. The program was based on equilibrium, compatibility and perfect bar-concrete bond. Complete details of this program can be reviewed in Rafi (2007). The theoretical ultimate loads for the BECS20 and BESS20-1 beams were determined with the help of this program using respective $f_{c}$. For the BECS20 beams, 


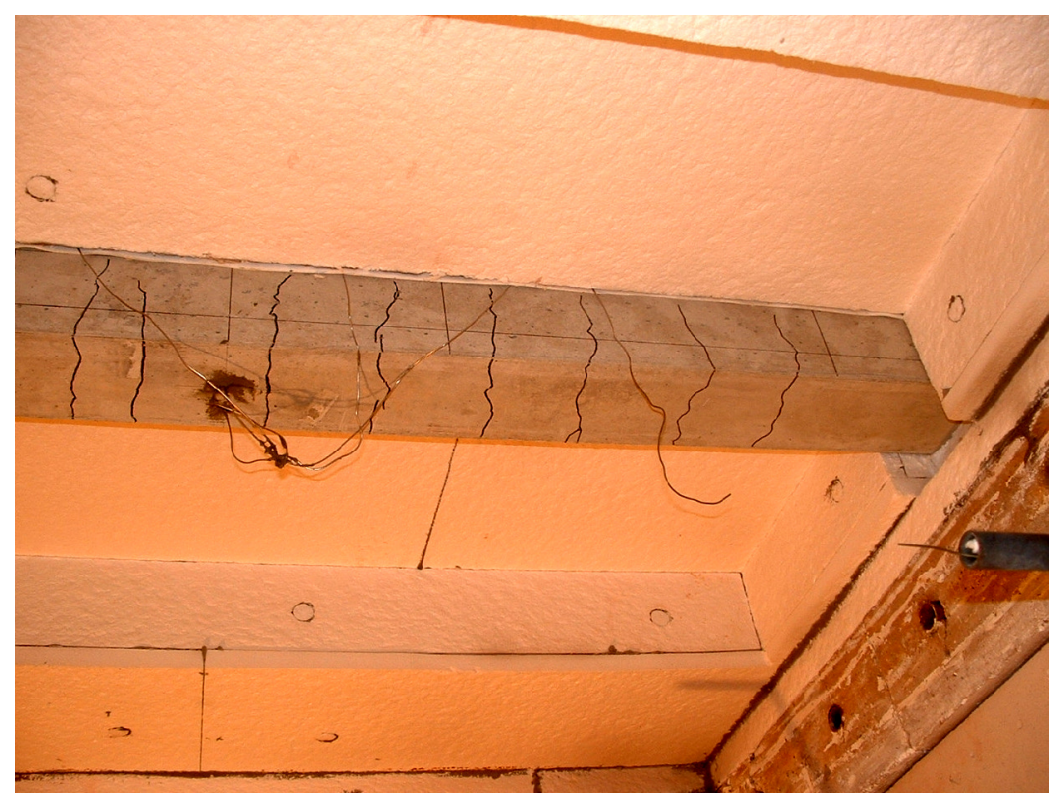

Fig. 3 View of beam BECS20-2 from inside furnace.

$40 \%$ of ultimate load at room temperature came out to be $30 \mathrm{kN}$. The same proportion of ultimate load was also applied to the BESS20-1 beam. The applied load for each elevated temperature beam is given in Table 3.

\section{Test procedure}

\subsection{Room temperature tests}

The specimens were placed on half-round supports, which were spaced at a distance equal to the test span of the beam. Loading was applied in small increments, through $38 \mathrm{~mm}$ diameter rollers, by means of a $200 \mathrm{kN}$ hydraulic jack. Steel plates were placed under each roller on the beam top in order to avoid local crushing. Each load increment was $2.5 \mathrm{kN}$ for the BRSS20 and 5 $\mathrm{kN}$ for the BRCS20 beams and was measured with a $200 \mathrm{kN}$ load cell. The ages of beams are provided in Table 1.

\subsection{Elevated temperature tests}

The beams were taken out from the conditioning room only at the start of their instrumentation and other test preparations. The load was applied to the beam at least half an hour before the start of heating and was kept constant during the entire period of testing. The loading force was transmitted to the beam through a pump.

The operator manually controlled the load, which was displayed on the monitor screen, and made the necessary adjustments to keep the load as constant as possible. The heating rate inside the furnace was in accordance with the ISO834 (1975) standard heating curve. The test was stopped after the load dropped on the beam and the concrete crushed on top, as discussed in the subsequent sections.
Table 3 Applied load and deflection of elevated temperature beams.

\begin{tabular}{|c|c|c|c|}
\hline Beam & $\begin{array}{c}\text { Applied } \\
\text { load } \\
(\mathrm{kN})\end{array}$ & $\begin{array}{c}\text { Initial } \\
\text { deflection } \\
(\mathrm{mm})\end{array}$ & $\begin{array}{c}\text { Final } \\
\text { deflection } \\
(\mathrm{mm})\end{array}$ \\
\hline BESS20-1 & 15.5 & 2.48 & 71.88 \\
\hline BECS20-1 & 30.0 & 8.57 & 25.93 \\
\hline BECS20-2 & 30.0 & 8.46 & 29.14 \\
\hline
\end{tabular}

\section{Analysis of test results}

The results presented in the subsequent sections are based on the beams used in this study. This study was aimed at investigating the beam behaviour up to failure, when using CFRP bars, and to provide requisite data for the development of numerical models. These results may not apply to beams different than used by the authors. Further tests on full-scale FRP RC beams are required to investigate the structural performance of these beams both at normal and high temperatures.

\subsection{Bond consideration at elevated tempera- tures}

The degradation in the mechanical properties of the constituent materials of a RC structure takes place when the structure is subjected to fire. The bond perhaps is the first mechanism likely to be affected at elevated temperature. A reduction of $40 \%$ in the bond strength of a steel bar was found at a temperature of $200^{\circ} \mathrm{C}$ whereas FRP bars may loose 80 to $90 \%$ of the bond strength in the temperature range of $200-250^{\circ} \mathrm{C}$ (Katz et al. 1999). 
The mechanics of deterioration of bond in FRP and steel $\mathrm{RC}$ structures differ in various aspects (at high temperatures) but common bond deteriorating factors also exist. For example, Katz and Berman (2000) found the escape of water pressure (which is generated at elevated temperatures) at the bar-concrete interface to be one of the factors that cause a reduction in adhesion for both steel and FRP rods.

In steel RC structures, the bond is highly dependent on the concrete strength where variation in the bond strength with temperature is roughly the same as the variation in the concrete compressive strength (Harmathy 1993, p. 44). FRP bars employ different surface treatments to increase the bond of otherwise smooth bars with concrete and polymer resin is an important part of most of these treatments. The bond strength of FRP bars with concrete relies on the properties of the surface layer and more importantly on the polymer at the bar surface (Bank et al. 1998). The loss of bond strength in FRP reinforced structures is not caused by the deterioration in concrete material properties (Katz et al. 1999). Two major factors that are likely to affect the bond of a FRP bar with concrete are given below.

\subsubsection{Resin and surface treatment}

Most fibre types are very resilient to heat and most do not burn even at significantly high temperatures. For example, carbon fibres can resist temperatures well above $1000^{\circ} \mathrm{C}$ (ACI 2001). The maximum bar temperature recorded during the test was $577^{\circ} \mathrm{C}$ for the BECS20-1 beam, which is nearly one half of the maximum specified temperature of $1000^{\circ} \mathrm{C}$. Also in the internal applications protection against direct exposure to fire and heat is provided by the concrete around the bars and the lack of oxygen reduces the possibility of burning of these composites. The fibres are bonded together with the help of a resin. Two categories of resins are commonly used. These include thermoset resin and thermoplastic resin. Both these types have very low softening temperature, which is termed glass-transition temperature, $\mathrm{T}_{\mathrm{g}}$ (ACI 2006). The major difference between these resins lies in the chemistry of thermoset resin, which is cross-linked to form a three-dimensional network. Although a significant reduction in the mechanical properties of thermosetting resins takes place at $\mathrm{T}_{\mathrm{g}}$, this is more gradual due to the polymer chain formation of the resin (Katz and Berman 2000). The softening of a resin could have detrimental effects on the performance of composite bars as it may cause a reduction in the transfer of force not only between fibres but also to the concrete. The melting of the resin could result in the loss of both strength and stiffness of a fibrous bar. $T_{g}$ depends on the type of resin but it has been found in the range of $65^{\circ} \mathrm{C}$ to $120^{\circ} \mathrm{C}$ (ACI 2006).

As mentioned earlier, the resin used in the CFRP bars was bisphenol epoxy vinyl ester with a manufacturer's provided $\mathrm{T}_{\mathrm{g}}$ of $96^{\circ} \mathrm{C}$. Since the deformations on the bar surface were formed by the resin only, it is apparent that the deterioration of bond takes place after $96^{\circ} \mathrm{C}$ and no bond can be expected at temperatures higher than $200^{\circ} \mathrm{C}$, as stated earlier.

\subsubsection{Coefficient of thermal expansion}

The coefficient of thermal expansion $(\alpha)$ of constituent materials can also affect the performance of a RC structure. Since the coefficients for both steel and concrete are quite similar, internal stresses, which may be generated at high temperatures due to differences in $\alpha$, are eliminated in steel RC. Polymers are anisotropic materials and have different $\alpha$ values in both the longitudinal and transverse directions. For example, CFRP bars have a coefficient of thermal expansion of $-9 \times 10^{-6}$ to $0.0 \mathrm{x}$ $10^{-6} /{ }^{\circ} \mathrm{C}$ and $74 \times 10^{-6}$ to $104 \times 10^{-6} /{ }^{\circ} \mathrm{C}$ in the longitudinal and transverse directions, respectively (ACI 2006). The coefficient of thermal expansion of concrete $\left(\alpha_{c}\right)$ is usually in the range of $7.2 \times 10^{-6}$ and $10.8 \times 10^{-6} /{ }^{\circ} \mathrm{C}$ (Mindness 1981). The transverse coefficient of a CFRP bar $\left(\alpha_{F T}\right)$ is thus approximately 10 times greater than $\alpha_{c}$. Thermal stresses $\left(\sigma_{T H}\right)$ are a function of the modulus of elasticity $(E)$, coefficient of thermal expansion and temperature change $(\Delta T)$, and can be worked out with Eq. (1).

$$
\sigma_{T H}=E \alpha(\Delta T)
$$

CFRP bars have an extremely low modulus of elasticity in the transverse direction $\left(E_{\mathrm{T}}\right)$ (Hollaway and Leeming 1999, p. 54). It can be seen in Eq. (1) that even a small temperature change can cause considerable stresses in the transverse direction, which may be greater than the tensile strength of concrete. As a typical example, take $\alpha_{F T}=74 \times 10^{-6}$ and $E_{\mathrm{T}}=5 \%$ of $E$ in the longitudinal direction (Table 2). The average tensile strength of concrete for the tested beams was found to be $3.10 \mathrm{MPa}$. Thus this strength will be reached in the transverse direction only at a temperature change of $6^{\circ} \mathrm{C}$.

These thermal stresses may produce radial cracks, which may not only affect the bar-concrete bond but also damage the concrete cover and cause splitting cracks (Gentry and Hudak 1996; Elbadry et al. 2000). However, no such splitting cracks were observed in any of the tested beams. One possible explanation is the presence of steel stirrups, which prevented the propagation of these cracks to the concrete surface.

\subsection{Modes of failure}

The design of beams was based on the ACI Code (2002; 2003). Following theses guidelines, the FRP reinforced beams were designed over-reinforced using a reinforcement ratio $(0.0070)$ greater than the balanced reinforcement ratio $(0.0032)$. The steel RC beams were under-reinforced beams having a reinforcement ratio (0.0077) lower than the balanced reinforcement ratio (0.0277). Therefore compression failure of the BRCS20 beams and tension failure of the BRSS20 beams was expected during their testing. These beams were tested at room temperature. 


\subsubsection{Room temperature tests}

The observed modes of failure of all beams are presented in Table 4 . The behaviour of both BRSS20 beams was similar they both failed through crushing of concrete after the tension reinforcement yielded and the BRCS20 beams failed in compression. In the BRCS20-1 beam the diagonal tension crack, which originated as a vertical crack at a distance of approximately $120 \mathrm{~mm}$ from the support, caused failure. The crack gradually bent over towards the point of load application as it propagated upward and became almost horizontal before reaching the load point. However, the beam kept taking the load as this diagonal tension crack propagated and opened up. Finally, the concrete above this crack crushed adjacent to the load point in the shear span, as shown in Fig. 4(a). The BRCS20-2 beam failed by the crushing of concrete between the point loads [Fig. 4(b)].

Table 4 shows the beam cracking loads $\left(P_{c r}\right)$. It can be seen that the cracking loads for all four beams are very close to each other, as can be expected. The ultimate load $\left(P_{u}\right)$ carried by the beam is also given in Table 4 and it can be noticed that the BRCS20 beams carried more than twice the load on the BRSS20 beams. This was due to the strength of the CFRP bars, which was much higher than the yield strength of the steel rebars (Table 2). The failure modes of BRSS20 beams are also shown in Fig. 4.
Table 4 Load, deflection and failure modes of ambient temperature beams.

\begin{tabular}{|c|c|c|c|c|}
\hline Beam & $\begin{array}{c}\mathrm{P}_{\mathrm{cr}} \\
(\mathrm{kN})\end{array}$ & $\begin{array}{c}\mathrm{P}_{\mathrm{u}} \\
(\mathrm{kN})\end{array}$ & $\begin{array}{c}\Delta_{\mathrm{u}} \\
(\mathrm{mm})\end{array}$ & $\begin{array}{c}\text { Mode of } \\
\text { failure }\end{array}$ \\
\hline BRSS20-1 & 7.8 & 41.9 & 29.16 & Steel yielding \\
\hline BRSS20-2 & 7.5 & 40.1 & 27.78 & Steel yielding \\
\hline BECS20-1 & 7.1 & 88.9 & 35.26 & $\begin{array}{c}\text { Shear } \\
\text { compression }\end{array}$ \\
\hline BECS20-2 & 7.1 & 86.5 & 35.50 & compression \\
\hline
\end{tabular}

\subsubsection{Elevated temperature tests}

The temperature progression of tension bars in the beams is illustrated in Fig. 5. The position of thermocouple on the bar is shown in Fig. 1. It can be seen in Fig. 5 that the temperature is independent of the bar material type, as expected.

Cracked concrete below the neutral axis (NA) is generally considered ineffective in resisting tensile stresses and the reinforcement is left to take tensile forces in this region. However the concrete surrounding the bars provides an effective cover and protects them from the external hazardous environment. Although rising temperature may cause a reduction in the properties of any reinforcing material, the mechanical behaviour of FRP bars

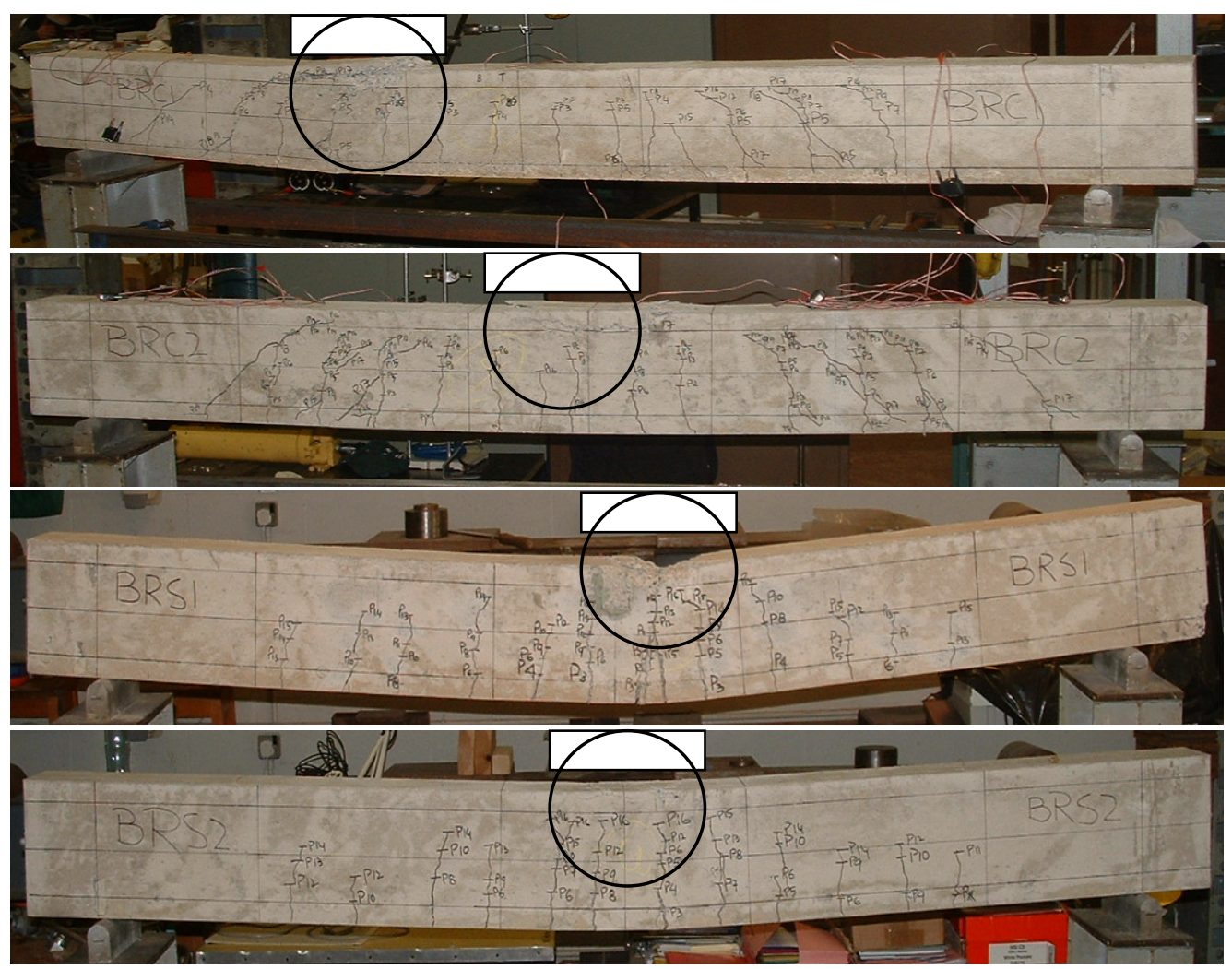

(a)

(b)

(c)

Fig. 4 Failure modes of room temperature beams. 
is different than steel at high temperatures. FRP bars can loose both their strength and stiffness due to the degradation in the resin at elevated temperatures. Kumahara et al. (1993) found a reduction of around $20 \%$ in the tensile strength of bars at a temperature of $250^{\circ} \mathrm{C}$ with a small decrease in the modulus of elasticity. Therefore it can be expected that the longitudinal strength of FRP bars is not significantly affected up to a temperature of about $300^{\circ} \mathrm{C}$. Degradation in polymer matrix begins at around $300^{\circ} \mathrm{C}$ (Gentry et al. 1998). FRP bar tensile properties decrease sharply beyond this temperature and may become negligible. A reduction of up to $60 \%$ in the tensile strength of FRP bars at a temperature of $400^{\circ} \mathrm{C}$ was noticed by Kumahara et al. (1993).

It can be seen in Fig. 5 that the rebar temperature of $400^{\circ} \mathrm{C}$ was reached after about $45 \mathrm{~min}$ of heating. Note that the cracks, which were formed due to the applied load before the start of testing, may provide direct access for heat to the beam interior, resulting in higher local temperature rise at these crack locations. Consequently, the bar temperature and hence rate of deterioration at crack locations may be greater than at any other point along the heated length.

A length of $225 \mathrm{~mm}$ at each end of the beam was outside the furnace and thus protected from the heat (Fig. 1). The beam was able to sustain the load and heat due to the anchorage provided to the bars in these cold ends even after $400^{\circ} \mathrm{C}$. The FRP bars at one end of the BECS20 beams slipped close to their failure. This caused an existing crack to open up and propagate upwards to cause a reduction in the compression zone. This crack was close to the point load in the one half of the beam where slippage of bars occurred. The concrete

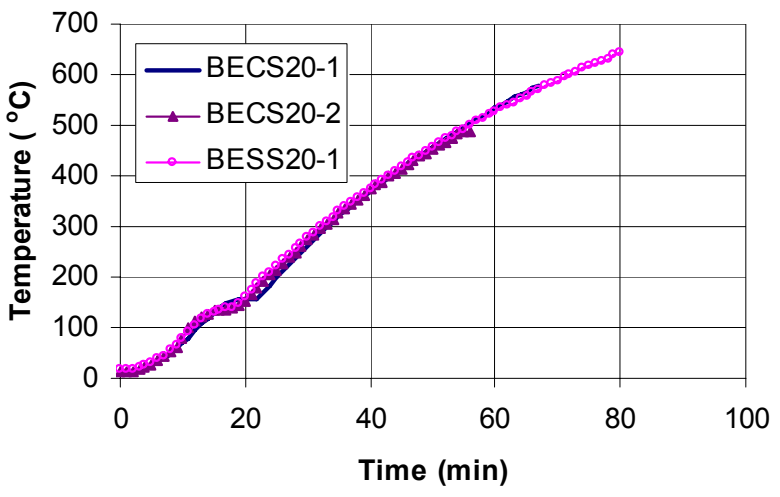

Fig. 5 Temperature development at rebar surface.

eventually crushed on top of this crack to cause beam failure. Figure 6 shows the BECS20-1 beam in the furnace after failure. The time-slip records of CFRP bars in the BECS20 beams are shown in Fig. 7. The measurements only at the end where slip took place are shown for clarity.

The BESS20-1 beam developed only few cracks at the initial load application. These cracks were relatively low in height and narrow in width. The mechanical properties of steel are also known to be reduced at elevated temperature. The chances of a large amount of heat penetration through cracks and hence deterioration of steel material properties locally were less in the BESS20-1 beam compared to the BECS20 beams. These properties thus degraded more uniformly with time and bars eventually yielded as the result of strain development. A couple of cracks at each end of the constant

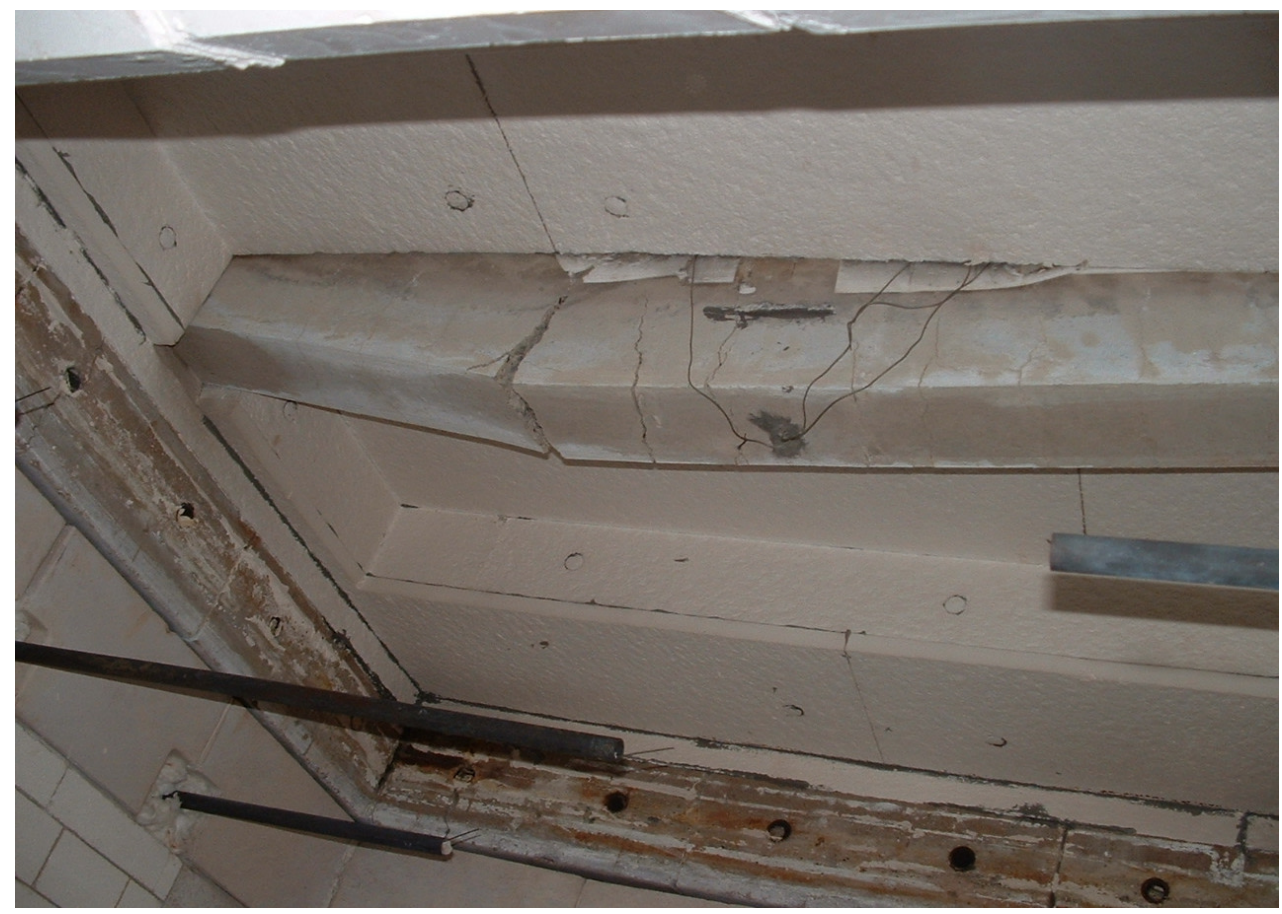

Fig. 6 BECS20-1 beam in furnace after failure. 


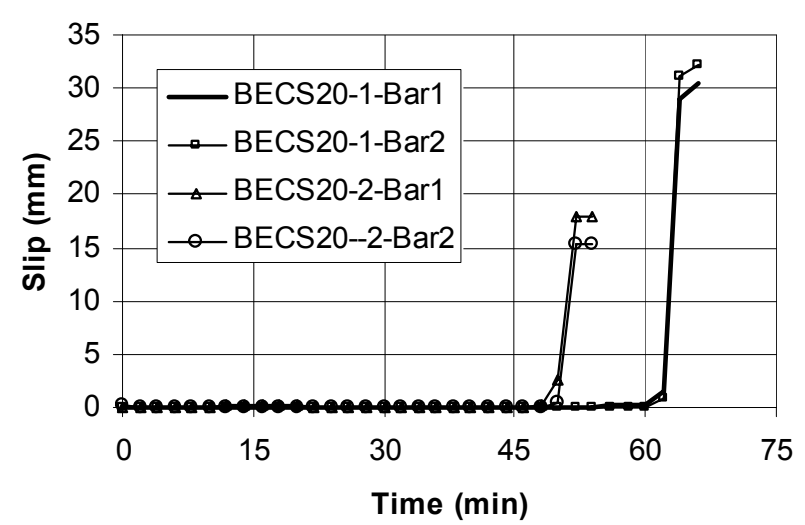

Fig. 7 Slip record of CFRP bars at beam end.

moment zone opened up and propagated upwards as the NA was pushed up. This reduced the area of concrete to resist compressive stresses and caused the concrete to crush on top. No signs of spalling or any breakage of concrete were seen in any of the beams tested at high temperatures.

\subsection{Deflection characteristics \\ 6.3.1 Room temperature tests}

Figure 8 shows the experimental load-deflection histories. The initial linear part of the curves has a very steep slope, which corresponds to the uncracked condition of these beams. In this region, the deflection is proportional to the applied load and the entire concrete section is considered effective in resisting the loads. As can be seen from Fig. 8, the behaviour of both types of beams is similar before cracking when the beams are stiff. The end point of this linear part is an indication of the initiation of cracking in the beam.

The next segment that immediately follows this linear part provides information about the bond quality and tension stiffening effects due to crack spacing. The

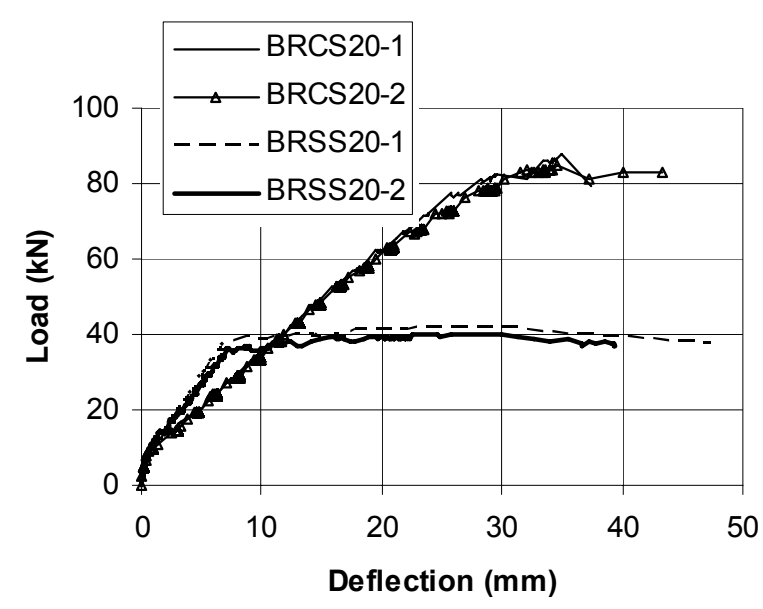

Fig. 8 Deflection behaviour of ambient temperature beams. slope of this part is smaller than the slope of the initial linear segment. This shows that the rate of deflection per unit load is higher after the beam has cracked, which is an indication of the reduction in the beam stiffness after cracking. Stiffness here is defined as load per unit deflection. However, it can be seen from the widening of the gap between the BRSS20 and BRCS20 curves in Fig. 8 that the rate of stiffness reduction of the BRCS20 beams grew higher with increases in load. The average difference in the stiffness of both types of beams at the yielding of steel bars was about $38 \%$. This can be attributed to the low elastic modulus of CFRP bars, which is $32 \%$ less than that of steel bars.

The last part of the curve is an indication of possible failure mechanism of the structure. As shown in Fig 8, both BRSS20 beams showed highly ductile behaviour and both beams failed at nearly the same load after undergoing considerable deformation with a very small increase in the load once the steel yielded. The ultimate load of BRSS20 beams was around 53\% lower than BRCS20 beams while the deflection of BRCS20 beams at the ultimate state $\left(\Delta_{\mathrm{u}}\right)$ was $25 \%$ greater than BRSS20 beams on the average (Table 4). The ultimate load here is considered as the maximum load carried by the beam. At failure, the deflection of BRCS20 beams was on the average 7\% less than BRSS20-1 beam, as can be seen in Fig. 8. This shows that up to the yielding of steel bars, BRCS20 beams deflected more than BRSS20 beams due to factors related to the low elastic modulus of CFRP bars. However, after yielding, BRSS20 beams exhibited a much faster rate of deflection than BRCS20 beams with a negligible change in load. It can be seen in Fig. 8 that some variations existed in the deflection at failure for each type of beam due to variations in the maximum concrete strain. Substantial deflection recovery was observed in the BRCS20 beams after the load was taken off. This shows that CFRP bars remained within the elastic range at the failure stage.

It can also be seen from Fig. 8 that the load carrying capacity of both BRCS20 beams dropped gradually after crushing of concrete. This shows that despite being over-reinforced, FRP reinforced beams can have a ductile failure mode as well as a kind of energy dissipation mechanism. The sudden drop in loads near failure as visible in the load-deflection curves of the BRCS20 beams was due to the opening of cracks.

\subsubsection{Elevated temperature tests}

The initial deflection of beams, which was caused by the applied load before the fire test is provided in Table 3. It can be seen in Table 3 that the initial deflection in the BECS20 beams was greater than that in the BESS20-1 beam, as can be expected from the above discussion on the deflection behaviour of room temperature beams. The beams were simply supported at their ends and were unrestrained both axially and rotationally before the heating test. The time-deflection history of beams after the start of the fire test is plotted in Fig. 9. 
Like many other materials, both concrete and steel expand at elevated temperature. However, longitudinal expansion of the beam was restrained by the cooler parts (including beam ends and top) that were protected from heating (Fig. 3). The beam thus became longitudinally restrained but rotationally unrestrained during fire. Consequently, any change in length due to the expansion of the heated part of the beam was also accommodated in deflection. Hence deflection during fire was comprised of deflection due to reduced flexural stiffness of the beam at elevated temperatures, bowing resulting from curvature, which was induced by thermal gradients, and deflection due to restraint.

Although the deflection after the application of heat increased for both types of beams, a marked difference in the deflection behaviour is apparent in Fig. 9 between the BECS20 and BESS20-1 beams. The deflection of the BESS20-1 beam increased linearly during the test and the rate of deflection became non-linear after $64 \mathrm{~min}$ of heating. The bar temperature at this time was around $552^{\circ} \mathrm{C}$ (Fig. 5). This non-linear deflection rise continued for around $16 \mathrm{~min}$ before concrete crushed after approximately $80 \mathrm{~min}$ of heating.

Mechanical strain on the rebar was produced only by applied load, before heating. After the beam was exposed to heat, total strain was the sum of mechanical strain due to applied load and mechanical strain due to the restraint provided by the cooler beam segments. Nevertheless, it is difficult to differentiate between the two types of strains. This is worth noting here that steel may have around $60 \%$ of its normal strength and stiffness properties left at a temperature of $500^{\circ} \mathrm{C}$ (Saafi 2002). The rapid deflection after this temperature during the test is an indication of the effects created by strain due to end restraints, which produced early yielding in the steel, and the beam eventually failed at a bar temperature of around $645^{\circ} \mathrm{C}$ when the steel could still have enough strength.

The failure of a flexural element in fire is considered to have taken place after specified performance criteria are violated. BS EN 1363-1 (1999) defines these criteria as the amount and rate of deflection, as given in Eq. (2)

$$
\begin{aligned}
& \Delta=\frac{L^{2}}{400 d} \mathrm{~mm} \\
& \frac{d \Delta}{d t}=\frac{L^{2}}{9000 d} \mathrm{~mm} / \mathrm{min}
\end{aligned}
$$

where $\Delta=$ deflection, $L=$ beam supported span, $d=$ effective depth, $T=$ Temperature and $t=$ time, respectively. The rate of deflection criterion in Eq. (2) is applied only after a deflection of $\mathrm{L} / 30$ is exceeded. The failure of beam BESS20-1 according to Eq. (2) is indicated with the help of a solid horizontal line in Fig. 9 where it is evident that the failure in this beam occurred at $79 \mathrm{~min}$. The deflection beyond $80 \mathrm{~min}$ in Fig. 9 was produced by the inertia of beam, which caused the beam to deflect further without taking any load.
Four different phases of the deflection curves for the BECS20 beams are apparent in Fig. 9. The deflection of these beams started to increase linearly similar to the BESS20-1 beam (after the application of heat) but with a smaller slope. The difference in slopes between the two types of beams may be due to the poor conduction of heat (Mallick 1988) across the diameter of the FRP bar, causing non-uniform changes in the stiffness properties with temperature, as well as negative thermal expansion co-efficient. This linear rise continued until around $14 \mathrm{~min}$ and $120^{\circ} \mathrm{C}$ of bar temperature was reached. The supplier provided $\mathrm{T}_{\mathrm{g}}$ of the $\operatorname{rod}$ as $96^{\circ} \mathrm{C}$ and heat distortion temperature of the resin as $104^{\circ} \mathrm{C}$. The rate of deflection beyond this time was very small until around 50 and $45 \mathrm{~min}$ in the BECS20-1 beam and the BECS20-2 beam, respectively. The bar temperature in these beams reached $457^{\circ} \mathrm{C}$ and $414^{\circ} \mathrm{C}$, respectively, at this time interval. As mentioned before, FRP bars lose most of the bond strength around a temperature of $200^{\circ} \mathrm{C}$. It is likely that the beam behaviour after a temperature of $120^{\circ} \mathrm{C}$ changed gradually from a beam to a tied arch, which was anchored by the FRP tie rod in the cold ends of the beam. This situation has been schematically drawn in Fig. 10 for the BECS20-1 beam. The shaded part of the beam in Fig. 10 shows uncracked concrete that represents the arch which is anchored by the tie rod at its ends.

The properties of tie bars deteriorated rapidly after a temperature of $400^{\circ} \mathrm{C}$. Consequently, the amount of thrust in the springing of this tied arch became considerable for the bond forces between rebars and concrete in the anchored zone to resist. The bars in the BECS20-1 beam thus started to slip at around 52 min of heating, as shown in Fig. 7. However, the beam kept taking the load for the next $11 \mathrm{~min}$. The deflection at this point increased linearly with increasing slope, as can be seen in Fig. 9. The tensile force transfer mechanism failed as the amount of bar slip increased. The deflection curve then turned nonlinear and deflection increased rapidly. The concrete crushed eventually on the top as the

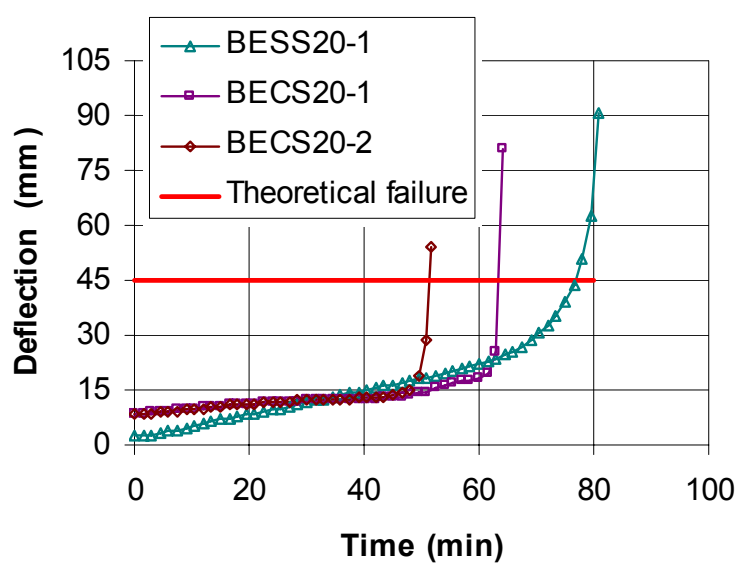

Fig. 9 Deflection characteristics of elevated temperature beams. 


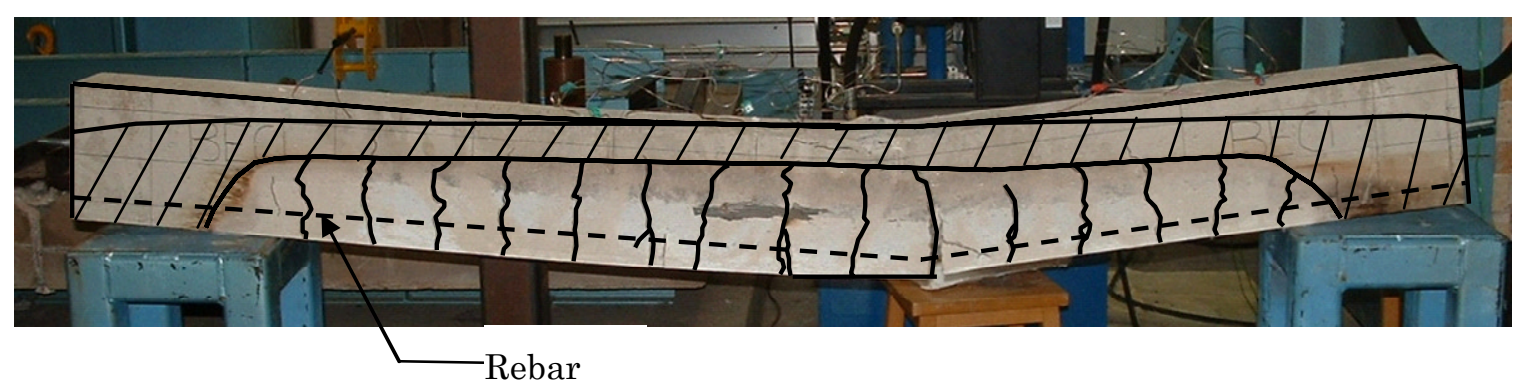

Fig. 10 Schematic of tied arch action in FRP reinforced beams.

propagating crack reduced the area of concrete to resist compressive stresses. The load on the beam dropped at this point. However the beam deflection did not stop as the beam deflected under its inertia and became a catenary on the top bars. The slip of bars also increased, even at a faster rate (Fig. 7).

In the BECS20-2 beam, the slip of bars initiated at around $45 \mathrm{~min}$ after the start of test and load on the beam dropped after 51 min of heating. The third phase of the deflection curve in this case was noticed only for a small interval of time before the deflection curve became non-linear, as can be seen in Fig. 9. The slip in both bars in the BECS20-2 beam initiated with a time lapse of around $4 \mathrm{~min}$. This may either be caused by the unequal load distribution to these bars owing to nonuniform deformation across the beam width or the slight difference in the anchorage lengths of the two bars, which arose during the casting process. It can be inferred that had the anchorage not failed both BECS20 beams would have lasted for an equal and longer time period. The failure times of the BECS20 beams according to the criterion as given by Eq. (2) were the same as those recorded (Table 3) and are indicated in Fig. 9. Again, full-scale fire tests are needed to study this behaviour of FRP reinforced beams and to determine to what extent this existing failure criterion applies to these types of beams.

\section{Conclusions}

The results of experimental testing of CFRP or steel reinforced concrete beams are presented in this paper. These beams were tested both at normal and elevated temperatures. Steel RC beams were used as control specimens. The main findings of this investigation are listed below:

1. Steel reinforced beams failed by steel yielding and FRP RC beams failed by concrete crushing. These were intended failure modes at ambient temperatures. Thus the failure modes were the same both at normal and high temperatures. The loss of anchorage of FRP bars at the beam end was a major contributing factor to the failure of a FRP reinforced beam at elevated temperature.

2. The cracking loads for the steel and FRP RC beams were nearly the same despite the fact that these are two differing reinforcing material types.

3. At ambient temperature, cracked FRP reinforced beams deflected more than the steel RC beams. However, after yielding of steel the rate of deflection in the steel beams was greater than that in the FRP beams.

4. No signs of any damage or splitting cracks due to the differences in the transverse thermal expansion co-efficient of CFRP bars and concrete were found owing to the preventive effects of the steel stirrups.

5. The restraint to the longitudinal expansion of the beam at elevated temperatures produced early yielding in the steel bars.

6. FRP RC beams were less ductile but stiffer than the steel reinforced beam during elevated temperature exposure. It can be inferred from the test results that it is possible for FRP reinforced beams to perform equally well in fire compared to steel reinforced beams.

It is understood that the conclusions and findings of this study are restricted to the CFRP bars used, the size of the beams, the shear span and the testing procedures executed. Further tests are needed to investigate the influence of other parameters such as concrete strength, anchorage length and beam shear spans on the behaviour of CFRP bar reinforced structures both at ambient and elevated temperatures.

\section{Acknowledgement}

The authors wish to acknowledge the support provided for this research by the School of Built Environment, University of Ulster and all the laboratory technical staff members.

\section{References}

Abdalla, H. A. (2002). "Evaluation of deflection in concrete members reinforced with fibre reinforced polymer (FRP) bars." Composite Structure, 56, 63-71.

ACI, (2002). "Building code requirements for structural concrete (ACI 318R-02)." American Concrete Institute, Detroit, Michigan.

ACI, (2003). "Guide for the design and construction of concrete reinforced with FRP bars (ACI 440.1R-03)." American Concrete Institute Detroit, Michigan.

ACI, (2002). "Guide for the design of externally bonded FRP systems for strengthening concrete structures 
(ACI 440.2R-02)." American Concrete Institute, Detroit, Michigan.

ACI, (2006). "Guide for the design and construction of concrete reinforced with FRP bars (ACI 440.1R-06)." American Concrete Institute, Detroit, Michigan.

Al-Salloum, A. Y. (1996). "Some design considerations for concrete beams reinforced by GFRP bars." In: H. Saadatmanesh and R.M. Ehsani, Eds. Proc. of First International Conference on Composites in Infrastructure, 1996. Tucson, Arizona, 318-331.

Al-Sunna, R. A. S. (2006). "Deflection behaviour of FRP reinforced concrete flexural members [online]." $\mathrm{PhD}$ Thesis, University of Sheffield. Available from: http://www.rss.gov.jo/publication.html [Accessed 24 February 2007].

Bank, L. C., Puterman, M. and Katz, A. (1998). "The effect of material degradation on bond properties of FRP reinforcing bars in concrete." ACI Material Journal, 95(3), 232-243.

BS, (1999). "Fire resistance tests, Part 1: General requirements (BS EN 1363-1)." British Standard, Brussels.

CSA, (2002). "Design and construction of building components with fiber reinforced polymers." Canadian Standards Association, Toronto, Ontario.

Elbadry, M. M., Abdalla, H. and Ghali, A. (2000). "Effects of temperature on the behaviour of fiber reinforced polymer reinforced concrete members: Experimental studies." Canadian Journal of Civil Engineering, 27(5), 993-1004.

Gentry, T. R. and Hudak, C. E. (1996). "Thermal compatibility of plastic composite reinforcement and concrete." In: M. M. El-Badry, Ed. Proceedings of 2nd International Conference on Advanced Composite Materials in Bridges and Structures, Montreal, Quebec 1996, 149-156.

Gentry, T. R., Bank, L. C., Barkatt, A. and Prian, L. (1998). "Accelerated test method to determine the long-term behavior of composite highway structures subject to environmental loading." ASTM Journal of Composite Technology and Research, 20(1), 38-50.

Harmathy, T. Z. (1993). "Fire safety design \& concrete." England: Concrete Design \& Construction Series: Longman Scientific \& Technical, England.

Hollaway, L. C. and Leeming, M. B. (1999).
"Strengthening of Reinforced Concrete Structures." England: Woodhead Publishing Limited, Cambridge, England.

ISO, (1975). "Fire resistance tests, elements of building construction (ISO-834)." International Standards Organization, Geneva.

JSCE, (1997). "Recommendation for design and construction for reinforced concrete structures using continuous fiber reinforcing materials." Japan Society of Civil Engineers, Concrete Engineering Series 23, Tokyo.

Katz, A., Berman, N. and Bank, L. C. (1999). "Effect of high temperature on bond strength of FRP rebars." Journal of Composites for Construction, ASCE, 3(2), 73-81.

Katz, A. and Barman, N. (2000). "Modelling the effect of high temperature on the bond of FRP reinforcing bars to concrete." Cement and Concrete Composites, 22, 433-443.

Kumahara, S., Masuda, Y., Tanano, H. and Shimizu, A. (1993). "Tensile strength of continuous fiber bar under high temperature." In: International Symposium on Fiber-Reinforced Plastic for Concrete Structures, SP-138, American Concrete Institute, Farmington Hills, Michigan 1993, 731-742.

Mallick, P. K. (1988). "Fibre-reinforced composites: Materials, manufacturing, and design." Marcel Dekker Inc., New York.

Mindness, S. and Young, F. J. (1981). "Concrete." Prentice Hall Inc., Englewood Cliffs, N.J.

Mota, C., Alminar, S. and Svecova, D. (2006). "Critical review of deflection Formulas for FRP-RC members." Journal of Composites for Construction, 10(3), 183-194.

Nawy, G. E. and Neuwerth, E. G. (1977). "Fiberglass reinforced concrete slabs and beams." Journal of Structural Division, ASCE, 103(ST2), 421-440.

Neville, M. A. (1981). "Properties of concrete." $3^{\text {rd }}$ ed. England: Longman Scientific \& Technical, England.

Rafi, M. M. (2007). "Fire performance of FRP reinforced concrete beams." $\mathrm{PhD}$ thesis, University of Ulster, UK.

Saafi, M. (2002). "Effect of fire on FRP reinforced concrete members." Composite Structures, 58, 11-20. 